\title{
Electromagnetic Forming Analysis of the Al 99.0 Sheet with Tools of Different Configurations
}

\author{
Dorin Luca ${ }^{1 . *}$, Cristina Biriș², and Dorian Luca $^{3}$ \\ 1"Gheorghe Asachi" Technical University of Iaşi, Faculty of Materials Science and Engineering, \\ Dimitrie Mangeron 41, Iaşi, Romania \\ ${ }^{2}$ University "Lucian Blaga" of Sibiu, Department of Industrial Machines and Equipment, \\ Emil Cioran 4, Sibiu, Romania \\ 3“"Gheorghe Asachi" Technical University of Iaşi, Faculty of Automatic Control and Computer \\ Engineering, Dimitrie Mangeron 27, Iaşi, Romania
}

\begin{abstract}
Electromagnetic forming is an advanced manufacturing procedure, characterized by the fact that the tool carrying the deformation force does not touch the workpiece. This paper presents research regarding the electromagnetic forming of Al 99.0 (EN AW-1200) sheet with coils, having different configurations. The purpose of the research was to find the flat spiral coil configuration that ensures maximum deformation of the workpiece. Flat spiral coils with different gaps between the coil and the workpiece, and coils with different number of windings were tested. The influence of these parameters was monitored on the maximum strain of the free bulged parts. The analysis of the results obtained for different configurations of the flat spiral coils allowed the selection of the significant parameters that influenced the electromagnetic forming process of the Al 99.0 flat workpiece, which aimed to elaborate the mathematical model and to optimize the investigated process.
\end{abstract}

\section{Introduction}

Electromagnetic forming (EMF) is a procedure applied to manufacture small parts by plastic deformation of some workpieces, in the form of metal sheet or tube.

The EMF of the flat workpiece (metal sheet) into a hollow part by Lorentz force is carried out by using a "punch" of special type. The "punch" is, in fact, a flat spiral coil. This tool is used for plastic deformation operations without touching the workpiece.

When plastic deformation is achieved by applying electromagnetic force, the best tool configuration must be found to achieve the maximum deformation of the workpiece material. Several aspects regarding the tools used for EMF are currently being investigated.

Deng et al. [1] have conducted studies on electromagnetic free forming (bulging) of AA5052 sheets with elliptical-shaped tools. The spiral elliptical coil is used with an elliptical cavity die, which shows that there must exist a correlation between the shapes of the two tools, namely the coil must be made the same shape as the die (part to be obtained).

Cao et al. [2] analyzed the effect produced by the use of an electrically conductive die in

\footnotetext{
* Corresponding author: dluca@tuiasi.ro
} 
the EMF process of the metal sheet. For the electromagnetic bulging system with a single coil, the authors concluded that the die material does not influence the deformation behavior of the metal sheet.

Liu et al. [3] investigated the effect of residual air from the die's cavity during the EMF of metal sheets. Resistance (opposed) of the residual air influences negatively the plastic deformation of the metal sheet, but the deviation of the obtained part may be reduced to less than $1.5 \%$, if the air pressure does not exceed $30 \mathrm{~Pa}$.

The effect of die's geometry on the formability of the 5052 aluminum alloy sheet electromagnetically formed was studied by Feng et al. [4]. The authors concluded that the formability of the 5052 aluminum alloy in the case of using a cylindrical die was considerably higher than when a hemispherical die was used.

To retain the edges of the flat workpiece, an electromagnetic pulsed blankholder system was designed, which was analyzed by the finite element method [5]. The simulation results show that the electromagnetic blankholder can generate a force of up to $1000 \mathrm{kN}$ depending on the discharge voltage of the capacitor bank.

Kim et al. [6] have experimentally and numerically studied the EMF process of aluminum alloy sheets with a rectangular helical coil. The study results showed that, unlike flat spiral coils that generate a low magnetic pressure in their center, the rectangular helical coil can generate a relatively uniform magnetic pressure which uniformly covers the working area.

This paper presents research regarding the EMF of Al 99.0 (EN AW-1200) sheet with coils, having different configurations. The purpose of the research was to find the flat spiral coil configuration that ensures maximum deformation of the workpiece.

\section{Experimental design and setup}

Increasing performance in the manufacturing processes involves finding the combination of optimal values of the technological parameters that act in those processes. In order to make the researches regarding the flat spiral coil parameters, proposed in this paper, the following experimental plans (EP) were established:

- EP 1: study regarding the influence of the gap between the coil and the workpiece on the maximum strain;

- EP 2: study referring to the influence of coil windings number on the maximum strain.

The data obtained from the preliminary experiments are subdued to dispersion and correlation analyses, applying statistical tests (Fisher, Cochran, Student) [7]. For this, experimental data is organized in table form and the sum, the average, and the dispersion (variance as a measure of dispersion) on the $m$ columns are calculated. Next, it is calculated the Fischer criterion, to establish the significant factors that are expressed by the rapport:

$$
F_{c}=S^{2} / S_{a}^{2}
$$

where $S_{a}^{2}$ is the dispersion caused by random factors, and $S^{2}$ is the dispersion given by the relationship,

$$
S^{2}=r S_{x}^{2}+S_{a}^{2}
$$

with $S_{x}^{2}$ the dispersion caused by the analyzed factor $X$ and $r$ the number of repeated tests.

The choice of values from the table for Fischer criterion is made based on the level of signification $\alpha$, and of the freedom degrees $v_{1}=m-1$ and $v_{2}=m(r-1)$. The signification level $\alpha$ (also called trust level) has been chosen according to the literature recommendations [8], with the value $\alpha=0.05$ (5\%), value that has been currently used for measurements in industry, laboratories, control operations, testing, expertise etc. 
In order to eliminate the dispersions that radically differ from the other variances, it is calculated the Cochran criterion, in order not to repeat the experiment, with the expression:

$$
G_{c}=\frac{\max S_{j}^{2}}{S_{1}^{2}+S_{2}^{2}+\ldots+S_{j}^{2}+\ldots+S_{m}^{2}} \quad ; \quad j=1 \ldots m
$$

where $S_{j}^{2}$ are the dispersions on the $m$ columns of the organized data table.

Values from the table for Cochran criterion are selected based on the level of signification $\alpha$, on the number of freedom degrees $v_{3}=m-1$ and the number of dispersions $m$.

Correlation analysis is used to estimate the connections between results and factors, and also for the selection of the significant connections that will be considered in the programmed experiment and will enter as variables in the mathematical model of the process. If it is to be found a certain connection, more or less tight, between the two variables $Y$ and $X$, it is to be said that these are in correlation or that there is a stochastic connection between them.

In order to express the connection between the two variables $Y$ and $X$, it was introduced an indicator, called coefficient of simple correlation, whose estimation $r_{y x}$ is determined with the relationship:

$$
r_{y x}=\frac{\sum_{i=1}^{n} x_{i} y_{i}-n \bar{x} \bar{y}}{(n-1) S_{x} S_{y}}
$$

where $S_{x}$ and $S_{y}$ are estimated squared medium deviations and $n$ is the number of tests.

Simple correlation coefficient squared is respectively called simple determination coefficient $\left(R_{y x}=r_{y x}^{2}\right)$ and it expresses that part from the variation of the result $Y$ that can be attributed to factor $X$.

After calculating the correlation coefficients, their significance is checked up. Thus, in the case of the simple correlation coefficient, it is used the Student criterion, which is expressed by the relationship:

$$
t_{c}=\frac{\left|r_{y x}\right| \sqrt{v_{4}}}{\sqrt{1-r_{y x}^{2}}}
$$

where $v_{4}=n-2$ is the number of freedom degrees and $n$ is the number of tests.

The experimental setup comprised the EMF equipment [9], a device for the electromagnetic bulging of the flat workpiece and disk specimens made from Al 99.0 (Fig.1). The main characteristics of the EMF equipment are: maximum capacitance of the capacitor bank $-200 \mu \mathrm{F}(4 \times 50 \mu \mathrm{F})$ and the maximum discharge voltage of the capacitor bank $-10 \mathrm{kV}$.

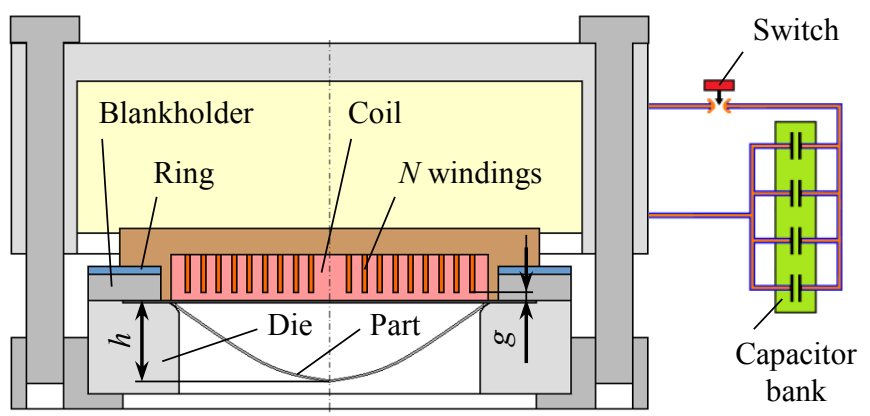

Fig. 1. Scheme of the EMF experimental setup. 
The device for flat workpiece bulging has, as its main elements, the flat spiral coil and the die. Five flat spiral coils having different number of windings with an outer diameter of $78 \mathrm{~mm}$ were used, made from a $10.1 \mathrm{~mm} \times 1.2 \mathrm{~mm}$ cross-sectional copper bar. The die is a ring with an inner diameter of $80 \mathrm{~mm}$ and a $5 \mathrm{~mm}$ connecting radius. In order to achieve different gaps between the coil and the workpiece, a set of spacing rings with different thicknesses was used, which were introduced between the coil and the workpiece.

\section{Results and discussions}

In order to determine the influence of the gap between the coil and the workpiece (EP 1), disk-shaped specimens made from Al 99.0 aluminum (EN AW-1200) sheet with a diameter of $110 \mathrm{~mm}$ and thickness of $0.50 \mathrm{~mm}$ were prepared. The specimens were free bulged on a die with the diameter of $80 \mathrm{~mm}$ and the connecting radius of $5 \mathrm{~mm}$. After deformation it was measured the forming depth $h$, obtained in the center of the parts with the help of a dial comparison with a precision of $\pm 0.01 \mathrm{~mm}$, resulting the values mentioned in Table 1 .

Table 1. EP 1 results: study regarding the influence of the gap on the maximum strain.

\begin{tabular}{|c|c|c|c|c|c|c|c|}
\hline \multirow{2}{*}{$\begin{array}{c}\text { No. of } \\
\text { repeated } \\
\text { tests }\end{array}$} & \multicolumn{7}{|c|}{ Factor levels (gap g, mm) } \\
\cline { 2 - 8 } & $\begin{array}{c}1 \\
(0.5 \mathrm{~mm})\end{array}$ & $\begin{array}{c}2 \\
(1.25 \mathrm{~mm})\end{array}$ & $\begin{array}{c}3 \\
(2.0 \mathrm{~mm})\end{array}$ & $\begin{array}{c}4 \\
(3.5 \mathrm{~mm})\end{array}$ & $\begin{array}{c}5 \\
(5.0 \mathrm{~mm})\end{array}$ & $\begin{array}{c}6 \\
(6.5 \mathrm{~mm})\end{array}$ & $\begin{array}{c}7 \\
(8.0 \mathrm{~mm})\end{array}$ \\
\hline $1(h, \mathrm{~mm})$ & 22.46 & 21.20 & 19.27 & 14.75 & 10.85 & 9.56 & 7.12 \\
\hline $2(h, \mathrm{~mm})$ & 22.65 & & 19.60 & & & & 7.33 \\
\hline $3(h, \mathrm{~mm})$ & 22.12 & & 19.44 & & & & 7.53 \\
\hline Sum & 67.23 & & 58.31 & & & & 21.98 \\
\hline Average & 22.410 & & 19.437 & & & & 7.327 \\
\hline Variance & 0.072 & & 0.027 & & & & 0.042 \\
\hline
\end{tabular}

The experimental data obtained was subjected to dispersion and correlation analyzes (Table 2), from which conclusions for the selection of the technological parameters resulted.

Table 2. Results of the dispersion and correlation analyzes for EP 1.

\begin{tabular}{|c|c|c|c|c|c|c|c|c|c|c|}
\hline \multirow{2}{*}{ Criterion } & \multirow{2}{*}{ Decision way } & \multirow{2}{*}{ Value } & $\alpha$ & $m$ & $r$ & $v_{1}$ & $v_{2}$ & $v_{3}$ & $v_{4}$ & $r_{y x}$ \\
\hline & & & 0.05 & 3 & 3 & 2 & 6 & 2 & 1 & -0.9999 \\
\hline$F_{c}$ & Eq. (1) & 4064.377 & \multirow{2}{*}{\multicolumn{8}{|c|}{$\begin{array}{l}\text { Discussion: because } F_{c}>F_{t} \text {, the factor gap is } \\
\text { considered a technological parameter and will be } \\
\text { included in the mathematical model }\end{array}$}} \\
\hline$F_{t}$ & from table & 5.14 & & & & & & & & \\
\hline$G_{c}$ & Eq. (3) & 0.51064 & \multirow{2}{*}{\multicolumn{8}{|c|}{$\begin{array}{l}\text { Discussion: because } G_{c}<G_{t} \text {, it results that the } \\
\text { hypothesis regarding dispersions homogeneity is } \\
\text { verified }\end{array}$}} \\
\hline$G_{t}$ & from table & 0.8709 & & & & & & & & \\
\hline$t_{c}$ & Eq. (6) & 290.0412 & \multirow{2}{*}{\multicolumn{8}{|c|}{$\begin{array}{l}\text { Discussion: because } t_{c}>t_{t} \text {, it follows that there is a } \\
\text { correlation connection between the gap factor and } \\
\text { the result obtained }\end{array}$}} \\
\hline$t_{t}$ & from table & 12.706 & & & & & & & & \\
\hline
\end{tabular}

The charge voltage level of the capacitor bank was $4 \mathrm{kV}$ and the total capacitance of capacitors was $200 \mu \mathrm{F}$, which provided deformation energy of $1.6 \mathrm{~kJ}$ for each test.

In the second experiment, flat spiral coils having different number of windings $N$, but the same outer diameter were used, which means that the pitch of the windings was different. The specimens used were discs with a thickness of $0.55+0.01 \mathrm{~mm}$ and a diameter of $110 \mathrm{~mm}$ from Al 99.0 aluminum (EN AW-1200). They were deformed on a die with 80 $\mathrm{mm}$ diameter and $5 \mathrm{~mm}$ connecting radius. The energy applied was the same for all deformed specimens $(1.6 \mathrm{~kJ})$. The desired result was, in this case as well, the forming depth $h$ measured in the center of the obtained parts, in order to ensure the operability of the tests. The data obtained from the experiment was centralized in Table 3. 
Table 3. EP 2 results: study referring to the influence of windings number on the maximum strain.

\begin{tabular}{|c|c|c|c|c|c|}
\hline \multirow{2}{*}{$\begin{array}{c}\text { No. of } \\
\text { repeated } \\
\text { tests }\end{array}$} & \multicolumn{5}{|c|}{ Factor levels (number of windings $N)$} \\
\cline { 2 - 6 } & $\begin{array}{c}1 \\
\text { (3 windings) }\end{array}$ & $\begin{array}{c}2 \\
(5 \text { windings })\end{array}$ & $\begin{array}{c}3 \\
(7 \text { windings })\end{array}$ & $\begin{array}{c}4 \\
(9 \text { windings })\end{array}$ & $\begin{array}{c}5 \\
(11 \text { windings })\end{array}$ \\
\hline $1(h, \mathrm{~mm})$ & 4.00 & 11.51 & 18.27 & 24.07 & 28.73 \\
\hline $2(h, \mathrm{~mm})$ & 3.78 & & 18.23 & & 28.95 \\
\hline $3(h, \mathrm{~mm})$ & 4.25 & & 17.92 & & 28.83 \\
\hline Sum & 12.03 & & 54.42 & & 86.51 \\
\hline Average & 4.010 & & 18.140 & & 28.837 \\
\hline Variance & 0.055 & & 0.037 & & 0.012 \\
\hline
\end{tabular}

The data from Table 3 were then subjected to the dispersion and correlation analyzes, which from resulted the conclusions presented in Table 4.

Table 4. Results of the dispersions and correlation analyzes for EP 2.

\begin{tabular}{|c|c|c|c|c|c|c|c|c|c|c|}
\hline Criterion & Decision way & Value & $\alpha$ & $m$ & $r$ & $v_{1}$ & $v_{2}$ & $v_{3}$ & $v_{4}$ & $r_{y x}$ \\
\cline { 4 - 7 } & & 0.05 & 3 & 3 & 2 & 6 & 2 & 1 & 0.99683 \\
\hline$F_{c}$ & Eq. (1) & 13400.46 & \multicolumn{2}{|l|}{$\begin{array}{l}\text { Discussion: because } F_{c}>F_{t} \text {, the factor } \text { number of } \\
\text { windings is considered a technological parameter } \\
\text { and will be included in the mathematical model }\end{array}$} \\
\hline$F_{t}$ & from table & 5.14 & $\begin{array}{l}\text { Eq. (3) } \\
G_{c}\end{array}$ & 0.52885 & $\begin{array}{l}\text { Discussion: because } G_{c}<G_{t} \text {, it results that the } \\
\text { hypothesis regarding dispersions homogeneity is } \\
\text { verified }\end{array}$ \\
\hline$G_{t}$ & from table & 0.8709 & $\begin{array}{l}\text { Discussion: because } t_{c}<t_{t} \text {, it follows that there is no } \\
\text { correlation between the variables } \text { or that the } \\
\text { dependence is nonlinear }\end{array}$ \\
\hline$t_{c}$ & Eq. (6) & 12.5239 & 12.706 & from table & &
\end{tabular}

Table 4 shows that the condition required by the Student criterion is not verified, which is why two additional determinations have been performed, with the same applied energy value but for two other values of the number of windings, the graphical representation of the data obtained and the regression equations determination. Figure 2 shows the variation in the forming depth of the free bulged parts when considering the average of the results referring to the three repeated tests from Table 3, as well as the singular test without repetition (test 1).

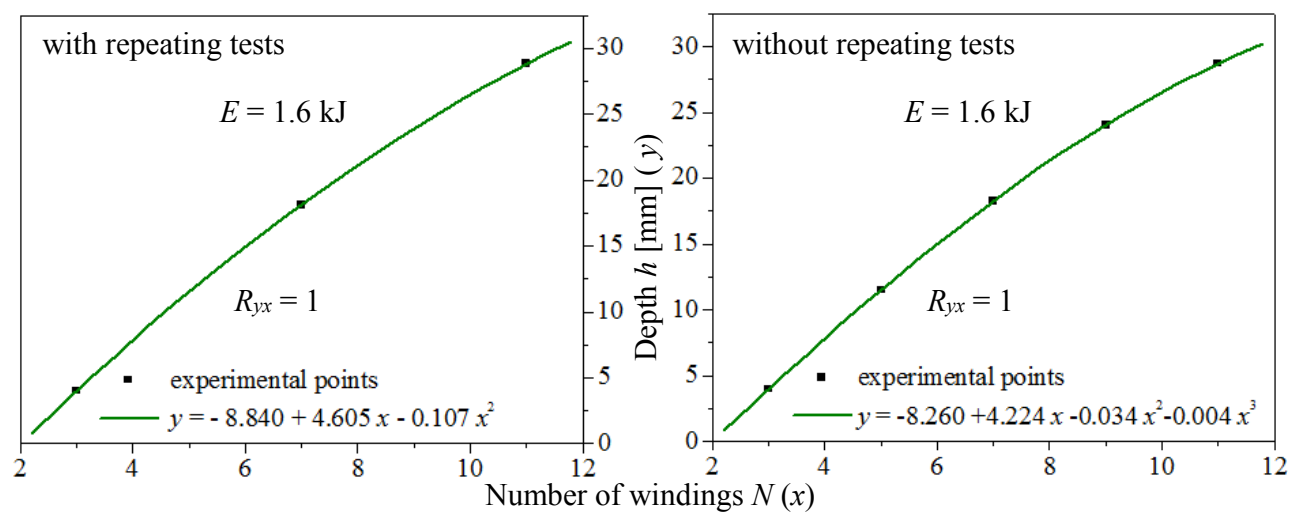

Fig. 2. Number of windings effect on forming depth.

The graphs presented and the established regression equations show the existence of a nonlinear dependence between the factor analyzed (number of windings $N$ ) and the obtained result (forming depth $h$ ), which is why $N$ can be selected as a technological parameter for the mathematical model of the flat specimen EMF process. 


\section{Conclusions}

The main conclusions of this paper are:

(1) The experimental results, presented in Table 1, confirm that while the gap $g$ between the coil and the workpiece increases, the obtained forming depth decreases. The pronounced decreasing of the forming depth (deformation degree) is produced if the distance $g$ has higher values than $2 \mathrm{~mm}$; However, reducing the distance $g$ to less than 2 $\mathrm{mm}$ increases the risk of damage to the flat spiral coil as a result of the electrical insulation penetration between the coil and the workpiece;

(2) The results, presented in Table 3 and Figure 2, show that with the increase in the number of windings of the flat coil, the obtained forming depth is increased. In the case of aluminum $\mathrm{Al} 99.0$ parts, by increasing the number of windings from 3 to 11, an increase, of about 7 times, of the forming depth was obtained;

(3) Performing tests and analyzing the statistical data allows highlighting the technological parameters that significantly influence the EMF process and the choice for them in order to establishing the mathematical model of the process.

(4) In order to obtain maximum strains in the Al 99.0 aluminum parts, it is recommended to use a flat spiral coil configuration with 11 windings and the gap, between the windings and the upper face of the workpiece, being $2 \mathrm{~mm}$.

\section{References}

1. H. Deng, Y. Mao, G. Li, J. Cui, J. Manuf. Process., 37, 595 (2019)

2. Q. Cao, Z. Li, Z. Lai, Z. Li, X. Han, L. Li, Int. J. Adv. Manuf. Technol., Published online: 05 November 2018, https://www.researchgate.net/publication/328756859

3. N. Liu, Q. Cao, X. Han, Y. Huang, X. Li, M. Chen, Liang Li, Int. J. Adv. Manuf. Technol., Published online: 19 March 2019, https://www.researchgate.net/publication/331874779

4. F. Feng, J. Li, R. Chen, P. Yuan, H. Su, Q. Zhang, P. Huang, Z. Zheng, Materials, 11, 1379 (2018)

5. Y. Huang, X. Han, Q. Cao, Z. Lai, H. Cai, N. Liu, X. Li, M. Chen, L. Li, Procedia Eng., 207, $347(2017)$

6. J.H. Kim, D. Kim, M.-G. Lee, Int. J. Adv. Manuf. Technol., 78, 825 (2015)

7. D. Luca, Proceedings of the $21^{\text {st }}$ International DAAAM Symposium, Vienna, 21, 1437 (2010)

8. C. Hurlin, Statistical Hypothesis Testing, Published online: November 20, 2015, https://www.univ-orleans.fr/deg/masters/ESA/CH/Chapter4_Inference.pdf

9. D. Luca, Environ. Eng. Manag. J., 17, 155 (2018) 